\title{
O ENSINO DE FUNÇÃO EXPONENCIAL NO ENSINO MÉDIO COM A UTILIZAÇÃO DO SOFTWARE GEOGEBRA: O ESBOÇO DE GRÁFICOS E A TECNOLOGIA DIGITAL COMO FERRAMENTA
}

\author{
TEACHING EXPONENTIAL FUNCTIONS FOR HIGH SCHOOL STUDENTS USING \\ THE GEOGEBRA APPLET: GRAPH SKETCHING AND DIGITAL TECHNOLOGY AS \\ A TOOL
}

\author{
VICTOR BALBINO DOS SANTOS ${ }^{a}$ \\ JÚLIA VIEIRA SOUSA ${ }^{b}$ \\ ELISABETH CRISTINA DE FARIA ${ }^{c}$
}

\begin{abstract}
Resumo
Este estudo teve como objetivo investigar o uso do Geogebra como ferramenta no ensino de função exponencial. Investigou-se como os alunos esboçam e analisam gráficos de função exponencial após utilizarem o software. Com isso, propusemos inserir a tecnologia digital como uma ferramenta em uma metodologia de ensino. Implementou-se uma sequência didática com três estudos dirigidos: no primeiro, os alunos participantes deveriam esboçar o gráfico sem maiores instruções; no segundo, utilizando o Geogebra; no último, realizar o esboço manualmente. A investigação identificou que os alunos partiram de suas intuições, perpassaram o uso analítico do software e consolidaram a compreensão do comportamento ao final do terceiro estudo. Concluindo, entre a construção por intuição e a análise do gráfico construído no software os alunos apresentaram boa evolução dos aspectos visuais das funções exponenciais, mas os elementos que requereram uma análise mais qualitativa não apresentaram avanços significativos.
\end{abstract}

Palavras-chave: Ensino de Matemática, Função Exponencial, Tecnologias Digitais, Geogebra.

\begin{abstract}
This study aimed at investigating the use of Geogebra as an instrument to teach exponential functions. The researched focused on how students sketch and analyze exponential function graphs after using the software. The proposal was to use the digital technology as a tool in a teaching methodology. A sequence of three activities was implemented: first, the students had to manually sketch the graph; Secondly, plot a function on Geogebra; Finally, another manual sketch. The investigation showed that students began relying on their intuition and were able to consolidate the understanding of the behavior of functions in the last activity. In conclusion, the evolution from the intuitive sketch and plotting the graph on the software to the final activity indicate significant evolution in the visual aspects regarding exponential functions, although the elements that require qualitative approach did not show similar progress.
\end{abstract}

\footnotetext{
${ }^{a}$ Secretaria Municipal de Educação e Cultura, Senador Canedo, Goiás, Brasil. E-mail: balbinovictor92@gmail.com

${ }^{\mathrm{b}}$ Escola Aprender Pensando. E-mail: juliavieira.sousa@hotmail.com

${ }^{\mathrm{c}}$ Universidade Federal de Goiás, Goiânia, Goiás, Brasil; ORCID: 0000-0001-5008-1898. E-mail: beth@ufg.br
} 
Keywords: Mathematical teaching, Exponential Function, Digital Technologies, Geogebra.

MSC2010: 9702, 97D40

\section{Introdução}

Esta pesquisa foi desenvolvida no âmbito do estágio curricular obrigatório do curso de Licenciatura em Matemática da Universidade Federal de Goiás (UFG), Campus Goiânia. A escola de campo foi o Centro de Ensino e Pesquisa Aplicada à Educação (CEPAE) da UFG. Acompanhamos uma turma de $1^{\circ}$ ano do Ensino Médio durante todo o ano letivo, dedicando o primeiro semestre à observação e um período de regência de doze aulas. A pesquisa propriamente dita, relatada neste artigo, foi desenvolvida no segundo semestre.

A investigação explora uma sequência didática com o uso do software Geogebra no processo de ensino e aprendizagem de funções exponenciais. Como destaca Maltempi (2008), as tecnologias digitais devem ser incorporadas ao ensino de Matemática, considerando suas adequações ao conteúdo e o contexto social dos alunos, não sendo validadas sem uma metodologia específica. Dessa forma, não objetivamos discutir o uso ou não de tecnologias digitais, mas como fazê-lo, no caso particular do software Geogebra e do conteúdo de função exponencial.

Não partimos de uma premissa determinista, na qual o software seria oportuno por si só, como uma espécie de panaceia. Como destacado por Moraes e Peixoto (2017), a análise centrada no papel das tecnologias incorre na exclusão das formas de produção e apropriação dos objetos técnicos. Assim, o foco da investigação é analisar como a sequência didática possibilitou que os alunos se apropriassem do conhecimento e utilizassem o software como uma ferramenta, numa perspectiva de compreender como este pode auxiliar o alcance dos objetivos de aprendizagem almejados para o ensino de funções exponenciais.

Durante o primeiro semestre do estágio, utilizamos o software nas aulas dialogadas, quando trabalhamos funções, de maneira geral, e função afim. Identificamos que o Geogebra foi uma ferramenta útil, pois podíamos realizar uma quantidade considerável de esboços a partir das dúvidas dos alunos. Por exemplo: utilizamos algumas leis de formação para dar significado ao coeficiente angular da função afim, 
isto é, para uma função do tipo $f(x)=a x+b$, mostrar o que acontece com o comportamento da função para valores cada vez maiores de "a". Um aluno indagou se para um valor de " $a$ " muito elevado, como 1.000.000, o gráfico da função seria próximo ao eixo vertical do plano cartesiano. A resposta para a dúvida do aluno poderia ser realizada por argumentação, mas identificamos que o recurso visual naquele momento foi significativo para a aprendizagem desse aluno e dos demais.

Quando trabalhamos com função afim, os alunos compreenderam que bastava criar dois pontos para realizar o esboço do gráfico. No entanto, tal método é insuficiente para outros tipos de função, como o caso de função exponencial. Assim, indagamo-nos como seriam os esboços e as análises acerca do comportamento de funções exponenciais. Isto é, os alunos atribuíram pontos aleatórios e depois iriam ligá-los? Fariam alguma consideração sobre os quadrantes em que os pontos aparecem? Mas principalmente, objetivamos identificar se após realizarem esboços de funções exponenciais no software Geogebra, se estas construções iriam subsidiar seus gráficos manuais futuros.

O intuito de realizar o ensino centrado no estudo gráfico é respaldada por Domingos:

\footnotetext{
Parece, assim, ser de especial importância uma abordagem do estudo das funções que coloca a sua principal ênfase na interpretação de gráficos e tabelas que privilegiem a relação entre variáveis da vida corrente, da Geometria, da Física ou de outras disciplinas. [...] Assim, o estudo analítico das funções em vez de se bastar a si próprio deve, pelo contrário, surgir com base em actividades sistematicamente feitas a partir de representações múltiplas (numéricas, tabulares, algébricas, gráficas, etc.). (DOMINGOS, 1994, p.12)
}

Em seu estudo realizado no início dos anos 1990, incorporando o uso de computadores ao ensino de funções, Domingos (1994) observou que alunos envolvidos no processo de aprendizagem utilizando o computador conseguiam reter os conceitos por mais tempo e que com estudos guiados a aprendizagem mediante raciocínio visual pode ser uma boa estratégia para o ensino de funções. Ainda, como defende McConnell (1995), a introdução ao ensino de variáveis deve ser feita num cenário bidimensional, em que se possa ver a relação entre as variáveis, não de maneira estática em que se manipula e resolve equações.

$\mathrm{Na}$ pesquisa desenvolvida, além da análise sobre função exponencial desenvolvida neste trabalho, foi empreendida uma segunda etapa, na qual realizamos uma investigação similar com função logarítmica. Sem embargo, a opção por expor 
apenas um tipo de função se deve à necessidade de adaptação ao formato de artigo. Para a parte de função logarítmica e a comparação entre os dois tipos de função, o leitor poderá consultar o relatório do estágio.

\section{Procedimentos Metodológicos}

A pesquisa foi realizada por meio de três estudos dirigidos (ED), que foram realizados antes de qualquer aula expositiva sobre gráficos de função exponencial, sendo estruturados da seguinte maneira: (I) na primeira atividade, os alunos deveriam esboçar o gráfico para a função exponencial e também redigir um breve relato sobre o que considerou para fazê-lo; (II) na segunda, o estudo dirigido foi realizado no laboratório de informática, em um estudo dirigido similar, o qual deveria ser respondido a partir do momento em que o gráfico fosse feito no Geogebra, com considerações sobre como o software serviu como ferramenta para o desenvolvimento da atividade; (III) finalizando a sequência didática, foi proposto um novo esboço de uma nova função exponencial e requerido um breve comentário sobre como o esboço foi realizado, como se diferenciou do realizado na primeira atividade e se o software foi útil no processo, após a realização do estudo II.

A análise dos instrumentos de pesquisa se deu de maneira qualitativa, com observação participante. Como destacam Lüdke e André (1986), a pesquisa qualitativa obtém seus dados descritivos através do contato direto do(a) pesquisador(a) com a situação ou o meio que irá estudar, preocupando-se mais com o processo do que o produto. De acordo com Triviños (2008, p. 137), “(...) o processo da pesquisa qualitativa não admite visões isoladas, parceladas, estanques. Ela se desenvolve em interação dinâmica, reformulando-se constantemente(...)". Com base nessas considerações, a ideia dos estudos orientados é permitir essa visão contínua e construtiva dos resultados dos alunos para se obter os levantamentos necessários.

\section{ED I:}

Neste primeiro estudo, trabalhou-se a função que relaciona o montante, $M$, de uma aplicação financeira (variável explicada) ao tempo, $t$, percorrido desde o início da aplicação. A lei de formação é: $M(t)=C \cdot(1+i)^{t}$, sendo requerido dos alunos que destacassem o domínio da função. $\mathrm{O}$ valor do capital inicial, $\mathrm{C}$, foi estabelecido em $\mathrm{R} \$ 1.000,00$. Para a taxa de juros, $i$, os alunos deveriam considerar duas alíquotas, $4,5 \%$ e 6,0\%, sendo requerido um esboço para cada taxa no mesmo plano cartesiano. Ao final 
da atividade, os alunos redigiram um breve comentário sobre o método utilizado para realizar o esboço. Foi permitido o uso de calculadora durante toda a atividade.

\section{ED II:}

O estudo realizado no laboratório aconteceu em dois dias diferentes, pois a sala não comportava todos os alunos. A lei de formação foi a mesma do estudo I, $M(t)=C \cdot(1+i)^{t}$, alterando-se apenas o capital inicial $(\mathrm{C})$, sendo $\mathrm{R} \$ 500,00$ na primeira aplicação e $\mathrm{R} \$ 700,00$ na segunda e as taxas de juros $(4,5 \%$ e 7,0\% com a primeira turma e 5,2\% e 8,0\% com a segunda). Ao final, os alunos foram indagados em qual estudo ficou mais perceptível compreender o comportamento da taxa de variação da função.

\section{ED III:}

No último estudo, a contextualização foi com estudos biológicos, mas manteve a mesma estrutura, com a seguinte lei de formação: $Q(t)=200 \cdot 2^{1,25 \cdot t}$, a qual relaciona a quantidade de bactérias existentes em recipiente, $Q(t)$, em função do tempo, $t$, sendo 200 a quantidade inicial e $2^{1,25}$ uma relação encontrada via modelagem matemática para caracterizar o ritmo de crescimento da população em função do tempo. Os alunos deveriam se atentar ao domínio da função antes de iniciar o esboço. Feito o esboço, outras duas questões indagaram se o fizeram de maneira distinta do que fora realizado no estudo I e se o estudo II, em que o software pode sem utilizado, influenciou o esboço de alguma maneira.

Para a análise dos resultados, selecionamos os estudos dirigidos de três alunos que fizeram todos os três estudos propostos. $\mathrm{O}$ critério se deu da seguinte maneira: (i) um aluno com gráficos que se assemelham ao comportamento real das funções; (ii) um cujos gráficos contém traços e elementos do comportamento, mas não se assemelham significativamente; (iii) outro aluno cujas construções não se assemelham ao resultado esperado. Estes alunos serão, doravante, denominados A, B e $\mathrm{C}$, respectivamente.

\section{Resultados e Discussões}

Os resultados de cada um dos três alunos selecionados são apresentados abaixo, de maneira individual, isto é, os resultados do aluno A são apresentados e discutidos, destacando-se os três estudos orientados, sendo o mesmo realizado para os alunos B e C, na sequência. 


\section{Aluno A:}

Para o primeiro estudo dirigido, os alunos deveriam construir dois gráficos no mesmo plano cartesiano, considerando uma taxa de juros em cada: $4,5 \%$ e $6 \%$. Como já destacado, foi permitido o uso de calculadora, de modo que os cálculos manuais não foram objeto de avaliação. $\mathrm{O}$ aluno A não se atentou ao requerido e fez cada gráfico em um plano separado, os quais podem ser vistos nas figuras abaixo: Figura 1 e Figura 2. Porém, na primeira construção, foram atribuídos apenas três números naturais consecutivos para a variável independente $t$. A escala utilizada não foi muito favorável, prejudicando a visualização da curva exponencial, levando o aluno a esboçar considerando uma leve inclinação.

Figura I- Esboço do gráfico 1 do aluno A do ED I

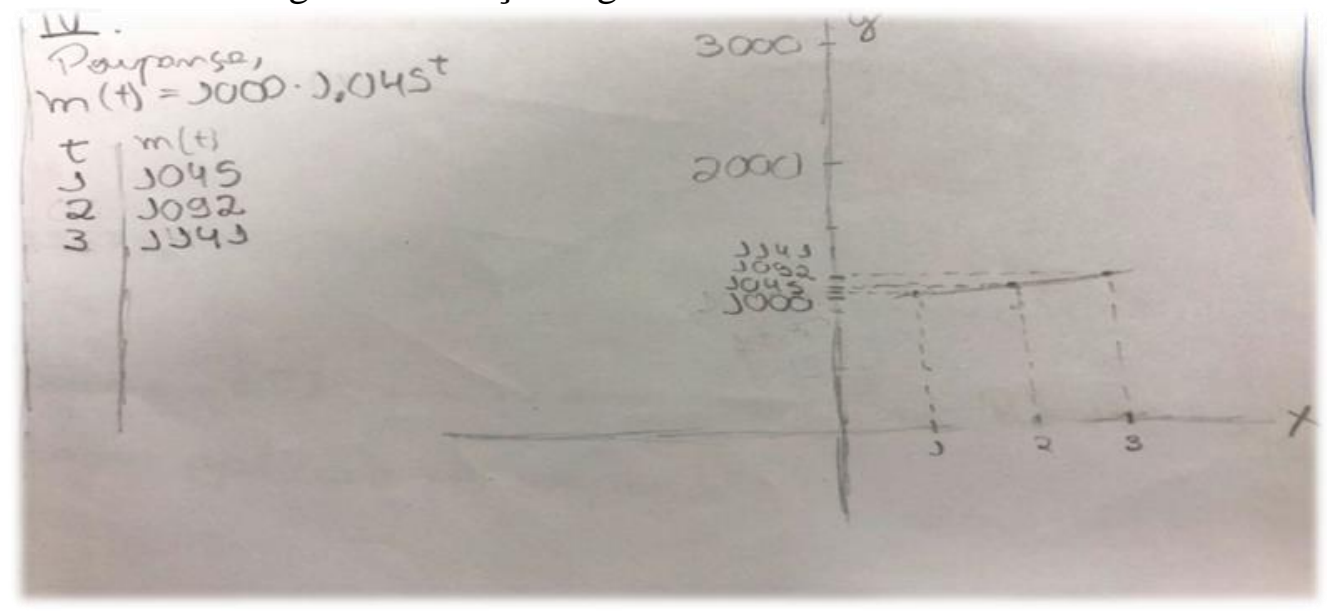

Fonte: Acervo dos autores

Assim como destaca Oliveira (2006), a escala inadequada prejudica o esboço, resultando em um gráfico não semelhante ao comportamento real da função. Porém, no segundo gráfico do mesmo estudo dirigido, o resultado difere do anterior, o que pode indicar que o aluno identificou que a estratégia adotada no primeiro não fora oportuna. Há, então, um maior espaçamento entre os pontos do Domínio escolhidos. 
Figura II- Esboço do gráfico 2 do aluno A no ED I

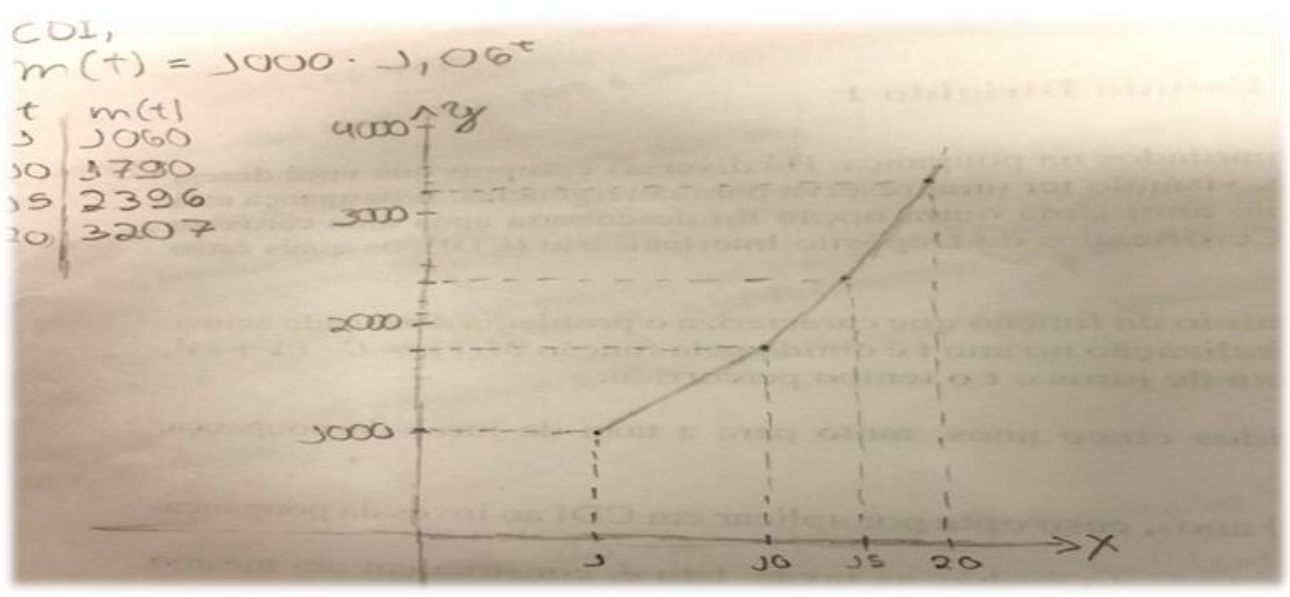

Fonte: Acervo dos autores

No relato que avalia como o gráfico foi esboçado, o aluno descreve que atribuiu valores distintos para a variável " $\mathrm{t}$ " e cita a mudança de escala do "eixo y" para que os números pudessem ser representados mais claramente.

No estudo orientado II, realizado no laboratório de informática, os alunos deveriam iniciar construindo o gráfico no software, bastando apenas digitar a lei de formação. Para tal, o resultado esperado seria o que pode ser visto na Figura 3, abaixo. No entanto, note que na imagem não há uma restrição do Domínio. Ao realizar o esboço manualmente, aparentemente foi intuitivo para ao aluno considerar apenas números inteiros positivos, haja vista que a variável em questão era o tempo, em anos. Todavia, no Geogebra, a preocupação para se restringir o domínio não foi pensada pelos alunos. Afinal, são percepções distintas ter o cuidado de analisar os valores atribuídos e simplesmente digitar a lei de formação e receber um gráfico pronto como saída. Afinal, para restringir o domínio, o aluno precisaria de raciocínio além e ainda precisaria identificar como realizar isso na linguagem do software. 
Figura III- Esboço no Geogebra do gráfico do ED

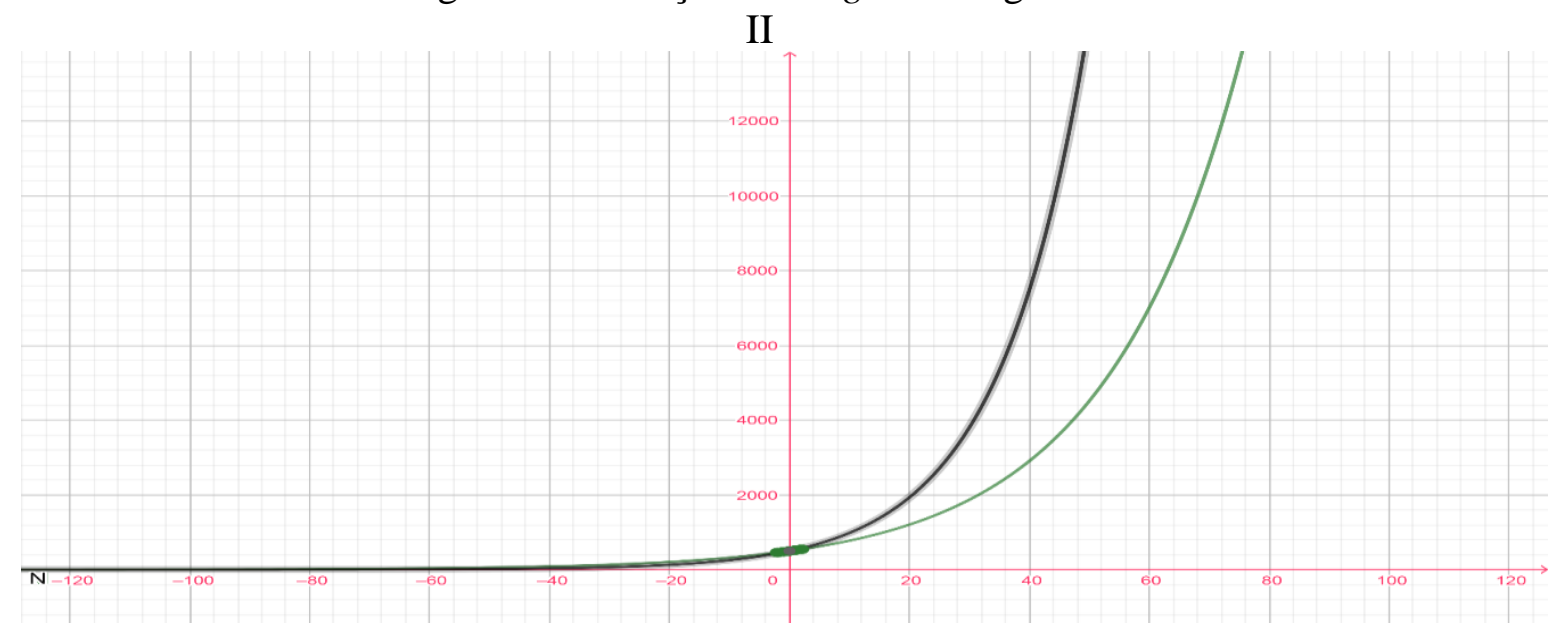

Fonte: Acervo dos autores

Na última questão em que há a indagação sobre o auxílio do Geogebra como ferramenta, o aluno argumenta que este dificultou o entendimento e que o procedimento sem ele foi "muito mais fácil". Essa resposta foi bem particular, e o único a defender essa opinião. Todavia, McConnell (1995) destaca que o uso de tecnologias no ensino da matemática desafia os professores a provocar em seus alunos a capacidade de julgamento, iniciativa e compreensão. Por ser um aluno que apresentou bom desempenho durante todo o estágio, não tendo dificuldades notáveis em Matemática, é possível que a dificuldade relatada com o software esteja ligada à operação deste e suas funções, podendo ser creditado ao pouco tempo destinado à sua exploração.

No último estudo sobre função exponencial, o aluno esboçou o gráfico da função atribuindo à variável independente números inteiros consecutivos, como pode ser visto na figura 4 abaixo:

Figura IV- Esboço do gráfico do aluno A no ED III

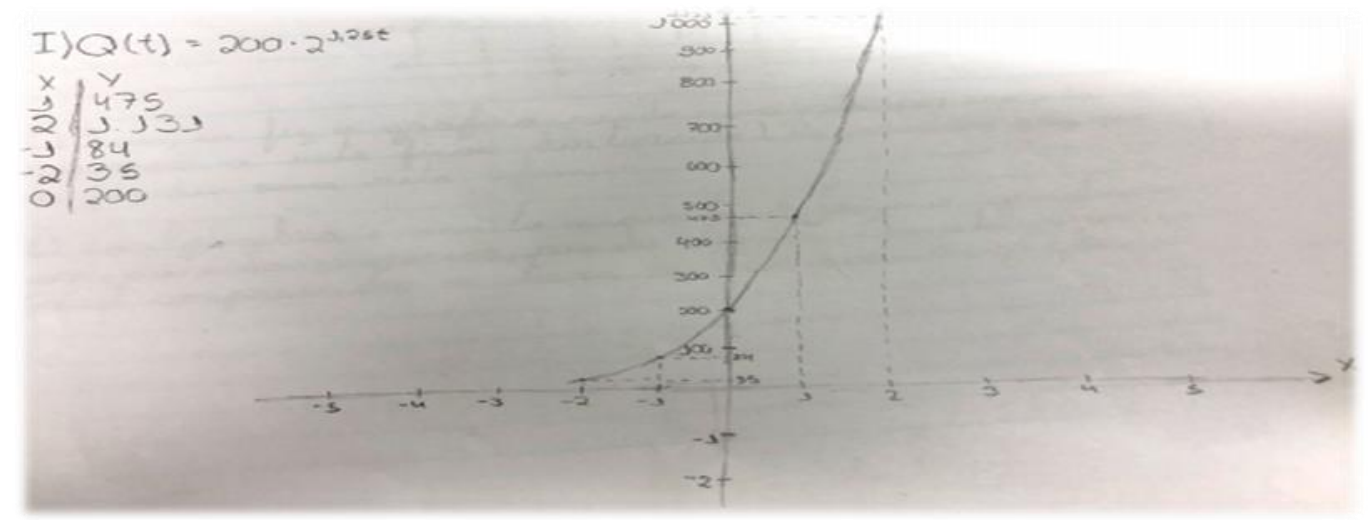

Fonte: Acervo dos autores 
Nota-se que o aluno não se atentou ao domínio, atribuindo valores negativos para " $t$ ", que é a quantidade de horas. Ele relata que não se lembra como esboçou o gráfico no primeiro estudo dirigido. Ainda, não expôs uma comparação às maneiras que fez os dois gráficos. Sobre a utilidade do software para a compreensão sobre o comportamento das funções exponenciais, afirma que com o software ficou mais 'evidente' e que neste esboço ele já sabia que o comportamento seria de uma curva e que devia se atentar à escala dos eixos para o esboço ficar mais nítido. Nota-se a partir desta resposta que no ED II o aluno ainda não havia identificado utilidade no software para a sua compreensão. Sem embargo, ao realizar um novo esboço, identificou que o uso lhe foi útil e seu gráfico ficou similar ao que fizera no ED II, pois não restringiu o Domínio, como havia feito no ED I.

Nota-se que o uso do software para este aluno teve prós e contras. Aparentemente foi possível internalizar o comportamento visto, o que é positivo. Todavia, como não houve restrição do Domínio no ED II, ao reproduzir o comportamento no ED III, essa desatenção com o Domínio se fez presente.

\section{Aluno B:}

O aluno B traçou retas para ambos os casos de taxas de juros trabalhados no ED I, como denota a Figura 5 abaixo:

Figura V-Esboço dos gráficos do aluno B no ED I

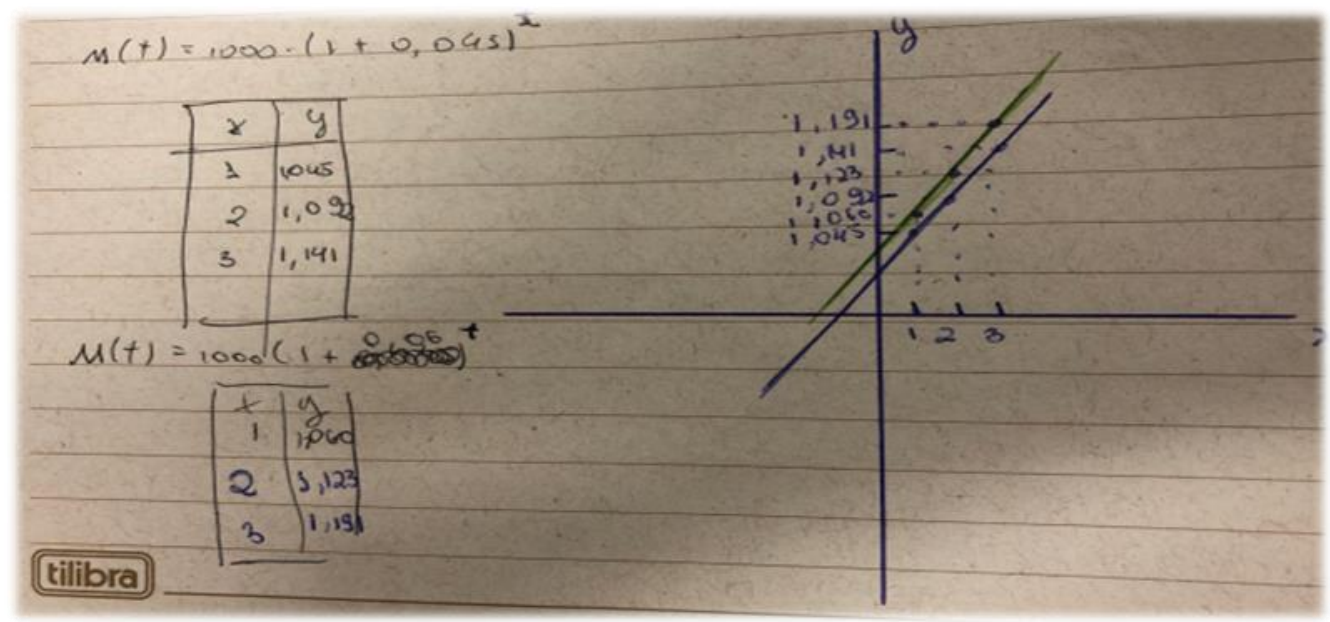

Fonte: Acervo dos autores 
Na primeira questão, este aluno conclui que “o domínio é o ' $t$ ', que significa o tempo percorrido" e o contradomínio é associado ao 'C', que ele mesmo conclui ser o capital inicial. Com isso, tem-se indícios de uma falta de consolidação do conhecimento sobre Domínio e Contradomínio de funções e a concepção sobre variável, assim como mostrado no gráfico em que as retas são traçadas considerando números negativos para a variável independente.

$\mathrm{O}$ aluno pressupõe a existência de valores negativos para a variável ' $\mathrm{t}$ ', mesmo afirmando que esta representa o tempo percorrido. Oliveira (2006) destaca a complexidade das notações de funções, destacando que estudantes podem confundir as 'letras' e não conseguir interpretar o significado destas, não diferenciando quais são constantes e quais são variáveis ao lerem a questão. Com isso, podemos identificar que o aluno não compreendeu a natureza do problema: uma variável dependente, montante, que é determinada pela independente, tempo. O capital assume o papel de uma constante, como destacado no enunciado deste ED.

No ED II, o aluno calcula as imagens apenas digitando os dados no Geogebra, sem anotar nenhuma resolução de cálculos. McConnell (1995) argumenta que a tecnologia permite aos alunos responder questões significativas de funções com apenas uma tecla. Todavia, a aprendizagem não deve ser apenas instrumental, mas sim holística, de modo que o software seja uma ferramenta que auxilie na compreensão, não na simples operação. Sem embargo, como o aluno destacou corretamente o Domínio, o Contradomínio e a Imagem da função, além de ter explicitados que todos os elementos do Conjunto Imagem são maiores ou iguais a 700, infere-se que a visualização no software pode ter auxiliado na compreensão da situação como um todo.

Nota-se que o conceito de taxa de variação ainda não havia sido compreendido, pois na questão em que se questiona como seria o gráfico, em caso de taxa de juros simples, $M(t)=C(1+i \cdot t)$, o aluno afirma que seria um gráfico linear, "com taxa maior de variação". Por fim, pontua que no software o comportamento foi mais perceptível e afirma que "amou" a atividade.

No ED III, ele atribui apenas três pontos positivos para o tempo, porém ao esboçar a curva, alonga a representação preenchendo também no segundo quadrante, conforme Figura 6, abaixo: 
Figura VI- Esboço do gráfico do aluno B no ED III

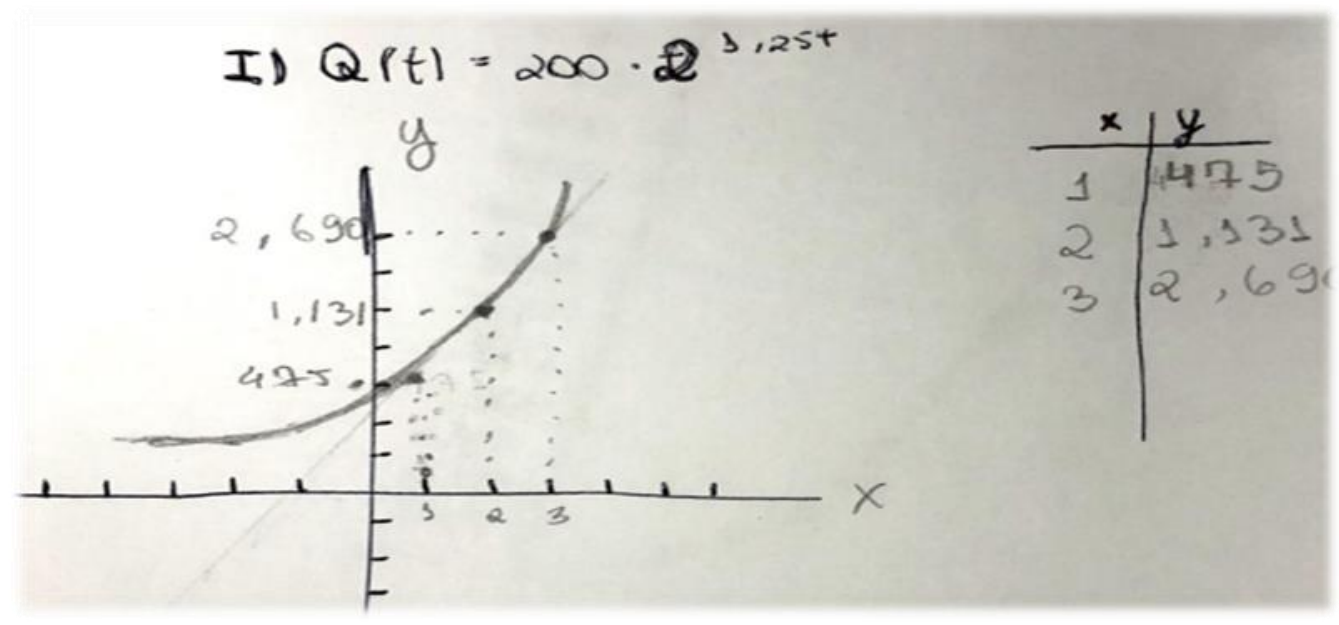

Fonte: Acervo dos autores

O aluno menciona que fez o ED I da mesma forma que este, atribuindo valores para "x" e "y", e que o Geogebra auxiliou a compreender o 'formato' do gráfico. Domingos (1994) afirma que na Matemática em geral, e nas funções em particular, o raciocínio visual tem papel importante, sendo possível notar esse impacto nos resultados do aluno, pois com o uso do software ele conseguiu abstrair o comportamento da função, refletindo na construção feita no ED III. Assim, no percurso dos estudos propostos, o aluno percebeu que ao ligar os pontos deveria fazê-lo com "alguma curvatura", justamente o comportamento de taxa de variação crescente, embora a concepção de taxa de variação não tenha ficado consolidado. A consideração de números negativos no Domínio retifica essa falta de consolidação de alguns elementos do estudo de funções exponenciais.

\section{Aluno C:}

No ED I, o aluno $\mathrm{C}$ fez os seguintes comentários sobre o Domínio e o Contradomínio da função trabalhada: os valores de " $t$ " seriam o domínio, e o contradomínio seria “a resposta de t”, ou o "resultado da função. É possível notar que a escala pode ter dificultado traçar o gráfico, devido ao posicionamento dos pontos, como registra a Figura 7. Ele cita que para esboçar o gráfico, "pensou em alguns números que poderiam ser o t" e aplicou os valores no plano. 
Figura VII- Esboço dos gráficos do aluno C no ED I

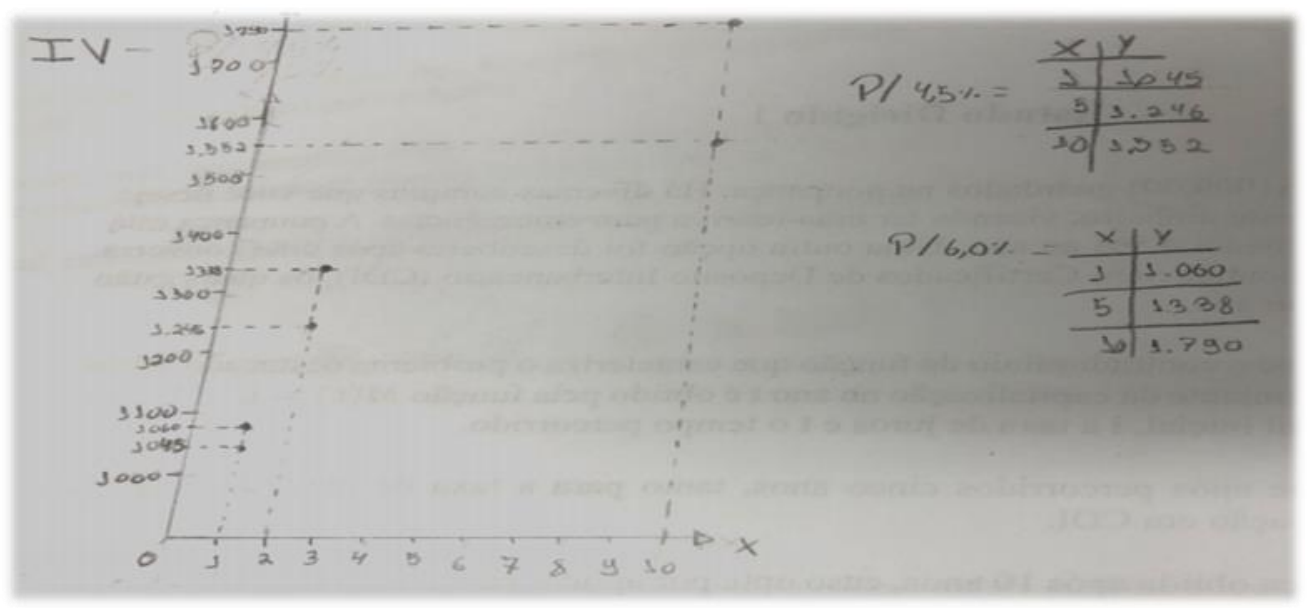

Fonte: Acervo dos autores

No ED II, o aluno C respondeu que o domínio da função é igual a 700 e o Contradomínio igual a zero. Assim, nota-se que mesmo após ter estudado outras funções e outros gráficos anteriores ao de exponencial, o conceito de função em si não foi consolidado, pois o aluno aponta valores específicos como sendo Domínio e Contradomínio, e não conjuntos que se relacionam. O aluno não identificou que a função de juros simples seria diferente da função com juros compostos e diz que a maior taxa de variação era a da função com o investimento de $8 \%$ de juros a.a. Ou seja, ele relacionou os dois gráficos das funções exponenciais com as taxa de juros diferentes, porém não esboçou no software o gráfico da função de juros simples, resultando em uma resposta não satisfatória. Este aluno argumentou que o Geogebra ajuda a construir o gráfico de maneira mais fácil e com maior precisão dos valores.

No último ED de função exponencial, o aluno $\mathrm{C}$ esboçou uma reta com apenas valores positivos para a variável independente, como mostra a Figura 8: 
Figura VIII- Esboço do gráfico do aluno C no ED III

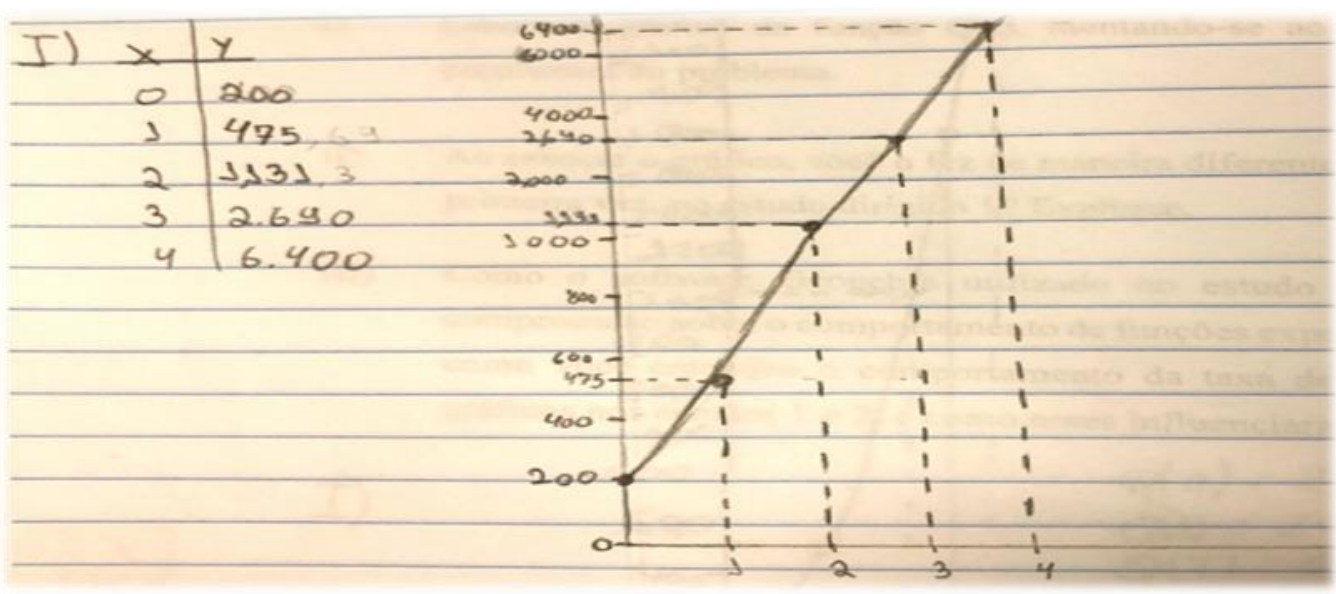

Fonte: Acervo dos autores

Ele argumenta que fez o gráfico diferente do primeiro ED pois o primeiro "deu uma reta afim" e neste fez o gráfico "sendo uma reta, porém ficou distorcida por causa da proporção", destaca.

O aluno aparentemente aprendeu o conteúdo de função afim, porém, não compreende (ainda) o novo conceito que lhe está sendo ensinado, transpondo repetidamente a ideia de que o gráfico será uma reta. Na última pergunta afirma que com o Geogebra é mais fácil fazer o gráfico, possibilitando perceber melhor a taxa de variação do esboço. A partir disso, refletimos sobre esta resposta frente ao esboço apresentado, pois o comportamento é de uma reta. Não obstante, pode-se notar uma evolução frente ao ED I, no qual o aluno não havia ligado os pontos que atribuiu.

\section{Conclusão}

Analisando os três estudos dirigidos da sala como um todo e em particular dos três selecionados para uma exposição mais detalhada, temos resultados que subsidiam a discussão sobre o uso do software como uma ferramenta e também sobre quais elementos não apresentaram uma consolidação significativa para a maioria dos alunos.

Em primeiro lugar, analisemos o esboço propriamente dito. A evolução nos gráficos criados se fez nítida para os alunos como um todo, resultado este representado pelos três aqui expostos. Conforme avançamos na sequência didática, consolidaram-se as noções do comportamento da função, com esboços destacando um crescimento 
vertiginoso, isto é, exponencial, com curvaturas similares ao real comportamento da função. Com isso, as considerações de Domingos (1994) e McConnell (1995) sobre a importância do aspecto visual e da análise bidimensional vão ao encontro dos resultados obtidos com a consolidação robusta do comportamento da curva.

Não obstante, em relação aos conjuntos inerentes ao conceito de funçãoDomínio, Contradomínio e Imagem- identificamos que não houve uma consolidação significativa, pois até mesmo alunos que fizeram a devida restrição do Domínio ao realizar o ED I, não o fizeram no ED III, embora a variável independente fosse a mesma: o tempo, que não admite valores reais negativos. Assim, como destacado por Maltempi (2008), o software por si só não possibilitou um pleno desenvolvimento do conteúdo trabalhado. Ainda, pelos resultados, somos levados a crer que com a falta de orientação o uso do software pode levar a equívocos, como identificamos na falta de análise do Domínio. Ou seja: ao simplesmente apertar os botões, como destaca McConnell (1995), a despreocupação com uma análise qualitativa leva a uma incompreensão do conjunto para o qual a função existe.

Em suma, podemos considerar que o uso do software pode ser incorporado na metodologia de ensino de funções exponenciais, mas deve estar alinhado à conceituação de todos os elementos pertinentes a esse conteúdo. O estudo sobre Domínio de funções é essencial para a compreensão de cada função trabalhada. Assim como destacado por Moraes e Peixoto (2017), o enfoque nas tecnologias digitais deve ser sobre a apropriação empreendida pelo aluno ao utilizar a ferramenta. Com a reflexão empreendida na investigação, identificamos em que medida os alunos se apropriaram dos esboços que realizaram com o uso da ferramenta e quais elementos do conteúdo não foram adequadamente compreendidos, requerendo novas propostas metodológicas.

\section{Referências}

[1] DOMINGOS, A. M. D. A aprendizagem de funções num ambiente computacional com recurso a diferentes representações. 1994. Tese de Doutorado. Universidade Nova de Lisboa: Faculdade de Ciências e Tecnologia.

\section{[2] LÜDKE, M.; ANDRÉ, M.E.D.A. Pesquisa em Educação-temas básicos de} educação e ensino. Pegagógica e Universitária Ltda-EPU, 1986.

[3] MALTEMPI, M. V. Educação matemática e tecnologias digitais: reflexões sobre prática e formação docente. Revista de Ensino de Ciência e Matemática, Canoas, v.10, n.1, p.59- 83, jan./jun. 2008. 
[4] MCCONNELL, J. H. Uso de computadores e calculadoras no aprendizado da álgebra. IN: COXFORD, A. F.; SHULTE, A. P. As ideias da álgebra, São Paulo: Atual, p. 49-69, 1995.

[5] MORAES, M. G.; PEIXOTO, J. Estado do conhecimento como perspectiva crítica para as pesquisas em educação: educação e tecnologias em questão. Revista Reflexão e Ação. Santa Cruz do Sul, v. 25, n. 3, p. 321-338, 2017.

[6] OLIVEIRA, F. C. Dificuldades na construção de gráficos de funções. 2007. Dissertação de Mestrado. Universidade Federal do Rio Grande do Norte.

[7] TRIVINÕS, A. N. S. Introdução à pesquisa em ciências sociais: Pesquisa qualitativa em educação. São Paulo: Editora Atlas, 2008, p. 116-173. 